\title{
Some Utilization of Project-based Learning for Vietnamese University Students of English in the Course "Intercultural Communication"
}

\author{
Hoang Huu Ngo \\ Vietnam National University, Hanoi \\ E-mail: hhoang161@yahoo.com
}

Received: February 11, 2014 Accepted: February 28, $2014 \quad$ Published: March 2, 2014

doi:10.5296/ijele.v2i1.5220 URL: http://dx.doi.org/10.5296/ijele.v2i1.5220

\begin{abstract}
This paper deals with implementing project work in the teaching of Intercultural Communication in English at Vietnam National University, Hanoi. It purports to be pragmatic in focus, linking theory with practice by providing Project-Based Learning as a tool for effectively teaching Intercultural Communication in English at the university.
\end{abstract}

Keywords: Project-Based Learning, project, project work, intercultural communication, approach, English

\section{Introduction}

At Vietnam National University (VNU), Hanoi, there has been a compulsory course named "Intercultural Communication" in the program of MA in English for over two decades. It is aimed to teach English majored students not only the use of this language but also intercultural communication skills. In other words, this course is tended to offer graduate students a practical application into life by using both language and communication skills once they have acquired knowledge from the subject area: Intercultural Communication. (IC)

However, a traditional theory-based approach is still used to teach this course including teacher-led classrooms for rote memorization. That makes the course ineffective and unpractical because too much theory is taught instead of practice and experience. In order to find out another more appropriate pedagogical approach, the researcher tries to use Project-Based Learning (PBL) for a pilot project to teach the course IC mentioned above. The following is a report about this project including (i) The Background: Theoretical foundations for PBL and English as a global language in relation to IC; (ii) The study: A report of some utilization of PBL application into teaching IC in terms of the 4 Ps: Project, People, Process 
and Product.

\section{The Background}

\subsection{From a Traditional Pedagogical Approach....}

In education, there is a common instructional approach by which teachers teach knowledge considered necessary and suitable to learners; the latter listen and try to take notes of what the former say in the classroom. In addition, learners have to learn what textbooks teach them to do. It has been a traditional pedagogical preference in all classroom levels in the world for thousands of years. It is likely a receptive approach, not productive at all. That approach seems even more "prominent" and popular in Vietnamese society where people are deep-rooted in the style of teaching and learning by repeating and repeating after teachers reading "three-word sentences" from an Old Chinese Manual for rote memorization. Of course, such an extreme way of education stopped a long time ago but its sequels still remain in the style of teaching and acquiring knowledge in schools in Vietnam.

In other words, a belief in learning theory rather than practice has been still strong among teachers and learners. Unfortunately, this instructional trend has gradually revealed more and more disadvantages in the context where knowledge is not within limit of the classroom lessons and not a "rumination" of what teachers and textbooks cater anymore. An obvious consequence from this trend is that learners may get more theory than practice so they tend to forget most things after class.

\subsection{To a Dynamic Innovative Approach: PBL or Learning by Doing}

In contrast to the traditional approach mentioned above, what learners need is practical knowledge that should be applied in life. That surely requires new and innovative approaches of which is PBL, namely, a model that organizes learning through "projects". By the name of this approach, the key term which cannot be missed is "project". It is defined in this context of pedagogy as a complex task, based on challenging questions or problems that involve students in design, problem-solving, decision making. (Jones, Rasmussen, \& Moffitt, 1997; Thomas, Mergendoller \& Michaelson, 1999). According to Carter and Thomas (1986), the implementation features of a project tend to include (1) Venue: Taking place outside the classroom; (2) Inter-disciplinary characteristic: Cross-curricular; (3) Students' autonomy: Allowing learners to set their own targets as they proceed. These characteristics point out that the reason why the term "learning" is used instead of "teaching" in the name "Project-based learning". In contrast to the teacher-based traditional approach, it signals this nature of an approach oriented to learners known as a requirement of working place-mainly outside the classroom, inter-disciplinary characteristic and autonomy as well as endeavor by students.

Thus, it leads to a merit that learners should experience something new by doing it themselves instead of simply receiving what is taught in the classroom in a "passive" manner. In other words, they learn by doing. That is, in order to acquire "actual" knowledge they really need, they learn while they do and they do while they learn with the help by teachers/textbooks rather than the dependence on what teachers/textbooks do and say in the classroom. 
Historically, that model was in fact not so new. It was traced back to the end of the $19^{\text {th }}$ century when Dewey (1987), who had initially promoted the idea of "learning by doing", argued:

The teacher is not in the school to impose certain ideas or to form certain habits in the child, but is there as a member of the community to select the influences which shall affect the child and to assist him in properly responding to these....... believe, therefore, in the so-called expressive or constructive activities as the centre of correlation.

Undoubtedly, to the above discussion, the model of PBL is defined as an instructional method centered on people (learners) in which a specific job that is self- assigned by learners with the help and consultancy by teachers, namely, a project. During a project, learners have opportunities to produce a product. Therefore, Freire (1985), Mezirow (1990) believe all learning relies on in the way we processed experience, especially a critical reflection of experience, in other words, it requires a process in which many activities happen simultaneously aiming at transforming what they learn into something practical to apply in actual life. In a word, that is the way adopting the pedagogical principle of exploratory learning, i.e. learning by experiencing. Learners acquire knowledge through some work with which they themselves define and decide what and how should be done; what it is done for.

\subsection{English as a Global Language in Relation to IC in Vietnam}

\subsubsection{Major Problems of Learning English in Vietnam}

Regarding English used as a foreign language in Vietnam, there are two major problems in the researcher's observation. First, unlike English as a second language context, the English in Vietnam is learned as a foreign language so most Vietnamese learners have few chances to use English everyday life. That leads to the fact that the Vietnamese have a lack of access to English and its availability input outside the classroom. Consequently, they have neither immediate necessity nor pressure to master the communicative skills in English in their life. Also, many educational language policies (often inappropriate) by authorities and some other causes make English unpractical and unintelligible. Second, Vietnamese people have a belief that English is a language just used to speak to English speaking people therefore what the latter say is right, what they do not say is wrong. In other words, Vietnamese people still pursue a native English speaker model while the control of this language is gradually shifting away from native speakers (David Crystal, 2004). That may make them quite good at communicating with English speaking people but get troubled in IC, where not only English speaking people but also the whole world speaks this language.

\subsubsection{IC Changing in English}

Fortunately, that situation is improving more and more. This is because globalization has present in Vietnam for several decades. It requires people use more and more English to communicate in intercultural contexts where Vietnam has been involved in business and many other interactive activities. Therefore, no matter what they think about the status of English, the people have had greater need and motivation to learn it for more diverse, 
practical and global targets. Thus, it is assumed to have a pedagogical model which promotes learners' English skills for global communication. In such a type of communication, English is an effective instrument language, namely, Lingua Franca, to use in IC in which the emphasis should be a real mutually cognitive contact between communicators rather a rumination/imitation of what English speaking people say and do.

As a result, it is likely an instructional curriculum of English should certainly include a training of IC skills taught on a base of the PBL approach in which the English language skills are not regarded as a target but a means that learners use to acquire knowledge and make this knowledge practical in such a contextual communication. That is, learners use English to contact whoever and acquire whatever they need without the possibility of the interference of their mother tongue. For that reason, practical activities must be more necessary than what is limited in the instructions of teachers and textbooks.

\section{The Study}

\subsection{Study Stages}

\subsubsection{Finding out a Problem}

A survey was conducted and it pointed out most previous students of the IC annual courses during the past years thought they got more theory than practice. They considered the subject interesting but in fact they had more little motivation and acquired fewer results than possible. This is because the way they were trained and acquired the knowledge from the subject was too "traditional". In this sense, like many other subject areas, the big problem of the IC courses at the university is "Learning is for learning".

\subsubsection{Setting up a Hypothesis}

From the student's comments and given the problem, a hypothesis was set up that the students were unmotivated due to the "traditional" permanent instructional approach so their learning outcomes were not good. Accordingly, in order to improve the situation in teaching IC, another approach should be used. That is a PBL one, which is regarded as being a suitable replacement approach for exploring and exploiting potential dynamic ability of learners in learning in general and in the subject area IC in particular.

\subsubsection{Forming a Pilot Course}

A pilot course was formed for the academic year 2012-2013. Thereby, more than $3 / 4$ of the time of the current syllabus was taught with the PBL approach to supply "real" and practical knowledge of intercultural communication for the students.

\subsection{The Four Letters Ps as a Guideline Analysis for the Study}

In order to fulfill what the course could offer and how it was processed, the following four cognitive letters Ps: Project-People-Process-Product were relied on and adhered to observations and analyses:

+ Project: The study course to be conducted; 
+ People: those who do the project;

+ Process: The arrangement of ways, things, venue and time in which the project is conducted;

+ Product: The outcomes of the project.

\subsubsection{The Project}

First of all, let us know about the previous annual course. As mentioned above, it is named "intercultural communication" organized for MA students majoring in English of the VNU, Hanoi every academic year since late 1990s. It is designed to introduce basic concepts and practice and awareness of inter cultural communication in English. It is aimed to offer various opportunities for students to explore how to communicate verbally and non-verbally between cultures. The most important role of this subject area which should be known about is not only to provide the students with English practice but also to supply them a clear understanding of cultural and contextual features which affect communicating between cultures.

A most striking benefit that the course can bring to the students is an understanding about different cultures that affect the way people live and communicate in the world. This understanding in turn offers students more IC skills. However, the learning outcomes have normally remained low. According to quite a number of integrated analyses based on the final test results, feedback by students, class observations, it can be seen that the students thought the subject area was useful but boring because there was too much theory some of which was far from what they need in their use of English. In this case, it was not very different from other classroom subjects, which were thought to bring more theory than practice in Vietnam.

From this observation, the researcher conducted pilot project course. In prerequisite, because the course was organized for English majored students, it was certainly assumed to require previous knowledge of English but not any knowledge of cultures. It would be provided later on during the course. This "action" course, which was named "Learn by doing to know cultures", had the specific topic "Cultural behaviors towards environmental protection". The topic referred both to the total social, cultural, political behaviors of a specific place in relation to the one of the wider geographical region of which it was part and to the national and global environment. The students themselves decided specific places. In a word, the overarching aim of the project was to implement some project work in order to make the students aware of the dangers of environmental pollution and of how to keep the environment clean and nice in the place they live in/learn in the way some other cultures have already done successfully.

\subsubsection{The People}

It goes without saying, all jobs need doers to fulfill them. However, in terms of PBL, the "people" here is a technical term (as the researcher's suggestion) denoting a trend to see participants, namely, learners as a center of the project conduct. That is, all the things done should be "of the people, by the people and for the people" (as a philosophical political view 
by Abraham Lincoln). The participants in this project were twenty MA English-majored students distributed into five groups so each group had evenly four members. They were teachers of all instructional levels, interpreters, institutional employees,... An advantage of this is that they were the people whose awareness (which was seen as a main part of a product after the project) may be easily diffused to other people if the course was successful. In other words, their practical knowledge after the project played a very important role because it was a part of training not only English but also an appropriate sense of intercultural communication in the community. If their IC skills were provided more and better, they would be the best disseminators of both language and global skills to those who wants to learn English as an instrumental language in the IC context.

However, their background of language and communication of the student participants was very various and subtle because they came from different universities of different regions of the country. Some were taught with a form-based approach, some were interested in communicative skills but had no interest in intercultural knowledge, some just saw the Anglo-Saxon based approach as a dominant one,... Consequently, when they came together to attend an MA program at VNU, some were good at English grammar and lexis (but a lack of fluency), some were fluent (but lack of appropriateness), some were too interested in a native speaker (-like) model (but this model of teaching English is a likely myth in terms of English as a global language versus English as a native language), etc. That might cause a difficulty in training for VNU.

The researcher (also the lecturer of the course) was of course belonged to the project people, that is, an indispensable source of inspiration and encouragement. However, he only had a role of being a facilitator rather than a "real" traditional knowledge provider.

\subsubsection{The Process}

\subsubsection{Steps}

The following four major steps of the project course were done:

(1) A time of structuring the project work including general instruction of IC knowledge; a formation of project groups and topics on the basis of the students' interests and needs; assigning member roles and coordinators for each group...

(2) A time of gathering information from various sources including a selection of appropriate information.

(3) A time of analyzing data gathered.

(4) A time of presenting and discussing the final reports.

\subsubsection{Activities in Detail}

The course had 45 hours divided into 2 portions. The first portion for the classroom instruction consisting of 10 hours lasted 3 weeks. At this time, the lecturer (also the researcher) and his students were also doing step (1). The "background concepts" of communication, culture, intercultural communication, globalization, verbal codes and 
non-verbal codes as means of human communication,... were gone through. Also, in this step, based on the above name of the project course, we decided to choose topics. It was based on the following criteria: (a) It could create chances for investigating, interpreting and critically analyzing the world. (b) It needed to be close to the students' interests, and particularly their everyday problems; (c) It could form a part of the immediate students' experiences after the course.

After a discussion, the students managed to decide to take this to lead the macro- project topic: The cultural values of the environment protection perceived by Vietnamese people in contrast to those by people in the world. By "Vietnamese people", each group might choose any specific group, community, city or district,... to investigate. By "people in the world", to give a contrast, each group might choose any country or region they like, in particular Asian countries. Finally, we had 4 micro-project topics which sound closest to the above criteria for the 4 groups each:

(1) A sense of protecting the environment by students at VNU, Hanoi in contrast to that by American students: Lessons drawn from observations.

(2) Culture shocks Westerners suffer from when living and facing the environmental pollution caused by Vietnamese people: Some suggestions for improvement.

(3)Why is Singapore thought to be a tidy island country: A lesson for Vietnam from the awareness of environment protection of Singapore.

(4) A disaster of sound environment pollution: How to raise awareness of lessening overuse of honks by Vietnamese people in traffic.

The second one was an action process with the other 35 hours lasting 12 weeks. During this time, each member of each group had 7 weeks to conduct his/her project outside the classroom to do step (2) and met the whole group each week to do step (3) in collaboration each week (possibly in the classroom or another venue but they had to inform the researcher their meeting place before). From week 8 to week 11, the course went on with step 4, i.e., the students presented and discussed their reports of what they had done during the previous 7 weeks. The last week was for evaluation.

\subsection{Products}

By acting through experience during the 15 action weeks, the students managed to learn not only about knowledge and elements of the core curriculum required but also extensively what they could observe and acquire from real life, actually not subject to the teacher in the classroom and textbooks. They could see, compare and contrast authentic global achievements with national problems/advantages. Accordingly, they thought and suggested what to solve or/and develop them.

\subsubsection{IC Skills}

The students managed to learn about cultural values and behaviors towards to environmental protections between cultures, to know about these issues in terms of inter-cultures and gained 
in-depth understanding of the global context in which all human behaviors are related and mutually affected. Cultural acts are not only what should be protected but also what needs to be criticized and eliminated in case they bring bad effects on the people's life and do not go well with human civilization. Therefore, they understood that some social behaviors to environment by people in Vietnam not only need to be found wrong but also need to be corrected according to the way of thinking and doing that the Westerners and the people in Southeast Asia (i.e. Singapore) have usually done.

Particularly, they understood that all they were aware of needed to be disseminated not only among the groups and but also other members in society. That is, they tried to apply what they had gained from the course for their country rather than what they had learnt just for learning in the classroom as before.

Also, they were aware that the concepts of culture and civilization are those which are closely related but which are in many cases not the same in definition. For instance, when observing the way others from different countries take part in traffic, they could find out the way people in Vietnam use vehicles honking was a negative cultural act which caused many bad effects to the community. In a sense of civilization, that was unacceptable. From this new awareness, they were sensitized about the problem associated with the destruction of the environment and thought about a need of getting rid of it to protect and develop the place where they live/learn. French people say, "To want is already to get a half of success". Indeed, once the students have had this half, how can they do in order to gain the other half? The answer is to make more "action" to do by trying to raise awareness of collaborative efforts by the people who live around them. The more the better! They are likely to go on with more actions now.

\subsubsection{English Skills}

In relation to language skills, in particular the speaking and listening skills had the greatest improvement. As it is known, Vietnamese students are not provided with opportunities to participate in real and authentic communication activities so they tend to focus on the language form and feel good and confident in grammar as well as theoretical analyses, which do bring very little good communicative competence. The reading and writing skills were also getting better thanks to the fact that they had to access the sources for preparation of discussion and presentation.

There was a very special thing that the students started to form a more and more different perception of using English. That is a perception of an international language used in international contexts by international people. In fact, thanks to a contact with many people from many countries during the project, they discovered all the things they used English to transfer to the hearer and to receive from the communicators was for an understanding and harmony rather than for an "English native-speaker likeness". "What I talk about and how I make the hearer understand what I mean is the maxim I think I should follow in IC", they answered in an informal interview by the researcher. As a result, they had more confidence to communicate thanks to discussions and exchanges of real life, real facts. Most students' discourse competence, developed not from single standard sentences but a connection of ideas to form a meaningful whole with specific strategies. A perception was more and more 
clearly formed that their language performance was just a "difference", not a "deficiency" (Jenkins, 2009).

\subsubsection{Research Skills}

The students improved their academic work through exploring and exploiting the resources they approached, developed and used knowledge of interdisciplinary work (language, culture, anthropology, sociology, etc.) much better than they had. They formed a research cycle with experience: doing their project beyond the classroom by observing facts and collecting the data then presenting what they did and set up a series of questions for discussion and argument when coming back to class. In addition, students began to be used to gathering good and appropriate information about national and international environment problems from a variety of sources (books, interviews, films,... or/and the internet).

\subsubsection{Social Skills and Collaborative Skills}

Nearly all students, regardless of language competence or motivational intensity, developed their social skills and collaborative skills dramatically. After the project work, they were clearly aware that being a group member entailed certain obligations. "I am an element of a system. I know that's a ring of a chain. If this ring was broken off, the whole chain would be broken, too", said a student. Most of them were also able to improve their collaborative skills by being responsible for the roles assigned, respecting others, following disciplines and regulations while acting in group. Particularly, they knew to know how to solve in-group conflicts.

\section{Conclusion}

What was presented above was part of utilization of the PBL approach as a replacement of the traditional way of teaching in an attempt to make the IC course more effective at VNU. It shows that PBL is very suitable for this area subject for that English is used as a work means. However, it is important to acknowledge the fact that the research with a small number of participants and what they did in the PBL approach was only a pilot case. It faced certain limitations. First, the fact the roles of teachers and students changed strikingly made some students and teachers uncomfortable with their project roles and process. Some students got difficulty in enjoying autonomy and accepting a new role of the teacher as a facilitator. Teachers might not know how to do as their role of facilitator as well. Second, a project with PBL might also be a controversial approach in such a Vietnamese context, where people, even university and governmental authorities, are deeply influenced by educational "rumination" tradition with current theory-based curricula and syllabuses. It may take them so much time to accept a perspective on which students themselves choose what to learn and work outside the classroom and get further knowledge away from what teachers and textbooks provide.

\section{References}

Carter, G., \& Thomas, H. (1986). 'Dear Brown Eyes': Experiential Learning in Project-Oriented Approach, ELT Journal, 40, 196-204. http://dx.doi.org/10.1093/elt/40.3.196 
Crystal, D. (2003). English as a Global Language (Second edition). Cambridge: Cambridge University Press.

Dewey, J. (1897). My Pedagogic Creed. Retrieved from http://dewey.pragmatism.org/creed.htm (June 15, 2013)

Freire, P. (1985). The politics of education: Culture power and liberation. MA: Bergin and Garvey Publishers Inc.

Jenkins, J. (2009). Current Perspectives on Teaching World Englishes and English as a Lingua Franca, TESOL Quarterly, 40, 157-181. http://dx.doi.org/10.2307/40264515.

Jones, B. F., Rasmussen, C. M., \& Moffitt, M. C. (1997). Real-life Problem Solving: A Collaborative Approach to Interdisciplinary Learning. Washington, DC: American Psychological Association.

McKay, S. (2005). Teaching English as an international language: Rethinking goals and approaches. Oxford: OUP

Mezirow J. (1990). Fostering critical reflection in adulthood: A guide to transformative and emancipatory learning. San Francisco: Jossey Bass.

Nunan, D. (1992). Research Method in Language Teaching. New York: CUP.

Thomas, J. W., et al. (1999). Project-Based Learning: A handbook for Middle and High School Teachers. Navato, CA: The Buck Institute for Education.

\section{Copyright Disclaimer}

Copyright reserved by the author(s).

This article is an open-access article distributed under the terms and conditions of the Creative Commons Attribution license (http://creativecommons.org/licenses/by/3.0/). 